\title{
Synthesis and Antitumor Activity of Novel Pyridoxine-Based Bioisosteric Analogs of trans-Stilbenes
}

\author{
Mikhail V. Pugachev, ${ }^{1}$ Thang T. N. Nguyen, ${ }^{1}$ Timur M. Bulatov, ${ }^{1}$ Roman S. Pavelyev, \\ Alfia G. Iksanova, ${ }^{1}$ Oksana V. Bondar, ${ }^{1}$ Konstantin V. Balakin, ${ }^{1,2}$ and Yurii G. Shtyrlin ${ }^{1}$ \\ ${ }^{1}$ Kazan (Volga Region) Federal University, Kremlyovskaya 18, Kazan 420008, Russia \\ ${ }^{2}$ I.M. Sechenov First Moscow State Medical University, Trubetskaya 8, Bldg 2, Moscow 119991, Russia
}

Correspondence should be addressed to Yurii G. Shtyrlin; yurii.shtyrlin@gmail.com

Received 9 March 2017; Accepted 31 May 2017; Published 6 July 2017

Academic Editor: Ponnurengam Malliappan Sivakumar

Copyright ( 2017 Mikhail V. Pugachev et al. This is an open access article distributed under the Creative Commons Attribution License, which permits unrestricted use, distribution, and reproduction in any medium, provided the original work is properly cited.

\begin{abstract}
A series of trans-6-phenylethenyl substituted pyridoxine derivatives, novel bioisosteric analogs of drugs based on trans-stilbene scaffold, were synthesized using the Wittig reaction of a bis-triphenylphosphonium pyridoxine derivative with various aromatic aldehydes. Two compounds demonstrated high activity against the estrogen-dependent MCF-7 (breast cancer) cell line with IC 50 in the range of 1.9-7.9 $\mu \mathrm{M}$ and very good selectivity for other studied normal and tumor cells, including the estrogen receptor negative MDA-MB-231 breast cancer cells. The active compounds possessed an intense blue fluorescence, and this feature allowed us to effectively visualize them in cytoplasm and in nucleus. The obtained results make the described chemotype a promising starting point for the development of new anticancer agents for the therapy of estrogen-dependent malignancies.
\end{abstract}

\section{Introduction}

Substituted derivatives of pyridoxine (vitamin B6) carrying alkenyl substituents at various positions of the pyridine ring represent interesting molecular structures with a rich bioactivity potential. In particular, pyridoxine molecules carrying a 5-ethenyl substituent possess anti-inflammatory properties [1], 6-phenylethenyl substituted pyridoxines have been described as purine receptor antagonists [2], and 2-ethenyl derivatives possess antitumor activity [3]. In our group, we have systematically studied the chemistry and biological activity of pyridoxine derivatives (e.g., [4-8]). Recently, we described a number of cis- and trans-5-alkenyl substituted pyridoxines which demonstrated promising antitumor activity [7]. In a more general context, variously substituted pyridoxine derivatives represent valuable therapeutic and diagnostic agents in actual therapeutic areas (for some examples, see [9-12]).

In this work, we studied a series of trans-6-phenylethenyl substituted pyridoxine derivatives for their cytotoxic activity against a panel of normal and cancer cell lines. The underlying idea was to design a novel chemotype of bioisosteric analogs of the well-known estrogen receptor targeting drugs such as diethylstilbestrol, tamoxifen, and raloxifene (Figure 1). All these drugs are bioisosteric mimetics of the natural estrogen receptor (ER) agonists such as estradiol (I). Their characteristic feature is the presence in their molecular structures of a trans-diarylethylene fragment (structures II-IV). These agents also typically contain the hydroxy or alkoxy groups at the remote axial positions of the molecule (e.g., at parapositions of phenyl rings). In some cases, for example, in tamoxifen, the hydroxyl groups appear as a result of metabolic transformations in human body. Such molecular features provide electronic and spatial compatibility to the ER active site. The mentioned drugs are clinically important ER modulators, widely used in the therapy of the estrogendependent malignancies. For example, diethylstilbestrol is an inexpensive and effective option for prostate cancer treatment before chemotherapy [13]. Persistently increased blood levels of estrogens are associated with an increased risk of breast cancer. Selective estrogen receptor modulators (SERMs), such as tamoxifen and raloxifene, are a class of compounds actively used for breast cancer prevention [14]. 


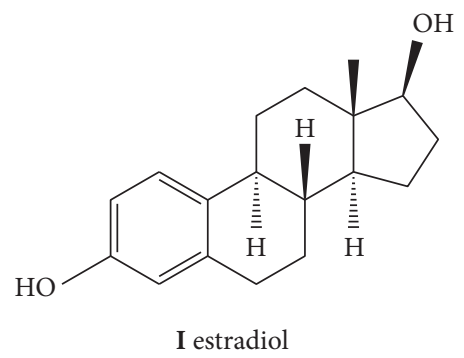<smiles>CCC(=C(CC)c1ccc(O)cc1)c1ccc(O)cc1</smiles><smiles>CC/C(=C(\c1ccccc1)c1ccc(OCCN(C)C)cc1)c1ccccc1</smiles><smiles>O=C(c1ccc(OCCN2CCCCC2)cc1)c1c(-c2ccc(O)cc2)sc2cc(O)ccc12</smiles>

III tamoxifen

IV raloxifene<smiles>[R]c1ccc(C=Cc2nc(C)c3c(c2C)COC(C)(C)O3)cc1[R]</smiles>

FIGURE 1: The natural ER agonist estradiol (I), examples of ER targeting drugs (II-IV), and compounds studied in this work (V); highlighted is the trans-diarylethylene motif characteristic of the bioisosteric analogs of the natural agonist.

Compounds of general formula $\mathbf{V}$ (Figure 1) studied in this work represent the substituted azaheterocyclic analogs of trans-stilbene. The presence in their structures of the characteristic trans-diarylethylene fragment makes them novel bioisosteric analogs of the natural and synthetic drugs based on trans-stilbene scaffold, and this feature prompted us to investigate their potential as selective estrogen-dependent cytotoxic agents. The synthetic route to compounds $\mathbf{V}$ has been reported in our recent work [8]. Herein, we report synthesis of one novel compound from this structural series and also describe biological and physicochemical properties of this interesting chemotype. In accordance with the underlying hypothesis, we have found that compounds of general formula $\mathbf{V}$, which contain the hydroxy or alkoxy groups at the remote axial positions of the molecule, possess high activity against an estrogen-dependent breast cancer cell line and very good selectivity for other studied normal and tumor cells. The obtained compounds also possess an intense blue fluorescence that makes it possible to visualize them in an intracellular environment. The obtained results suggest promising potential of the active compounds as new anticancer agents potentially useful in the therapy of the estrogendependent malignancies such as breast cancer or as novel fluorescent probes for molecular biological applications.

\section{Materials and Methods}

2.1. Synthetic Procedures. Chromatographic purification of compounds was carried out using column chromatography on Acros silica gel (60-200 mesh). Reaction progress and purity of compounds were monitored by TLC on Sorbfil PTLC-AF-A-UF plates. Melting points of the products were determined using a Stanford Research Systems MPA100 OptiMelt appliance. ${ }^{1} \mathrm{H}$ and ${ }^{13} \mathrm{C}$ NMR spectra were recorded on a Bruker Avance 400 spectrometer (400.17 and $100.62 \mathrm{MHz})$. Signals of chloroform $(\delta \mathrm{H} \mathrm{7.26,} \delta \mathrm{C} 77.16)$ were used as references in the ${ }^{1} \mathrm{H}$ and ${ }^{13} \mathrm{C}$ NMR spectra. Coupling constants $(J)$ are reported in Hz. HPLC/MS-experiment was 
carried out using a Triple TOF 5600, AB Sciex superhigh resolution mass spectrometer from the solution in methanol by turboionic spray (TIS) ionization method with the collision energy with nitrogen molecules of $10 \mathrm{eV}$. The excitation and emission spectra have been recorded using TECAN M200 Pro plate reader.

Synthesis and analytical characteristics of compounds $\mathbf{4 a}$, $\mathbf{b}, \mathbf{5 b}$, and $\mathbf{6 a - c}$ were reported in our recent papers $[7,8]$.

(E)-6-(4-Hydroxy-3-methoxystyryl)-2,2,5,8-tetramethyl-4H[1,3]dioxino[4,5-c]pyridine (4c). Sodium hydride $0.22 \mathrm{~g}$ $(9.0 \mathrm{mmol})$ and 4-hydroxy-3-methoxybenzaldehyde $0.46 \mathrm{~g}$ $(3.00 \mathrm{mmol})$ were sequentially added to a solution of $1.20 \mathrm{~g}$ (1.5 mmol) 5,6-bis(triphenylphosphonio(methyl))-2,2,8-trimethyl-4H-[1,3] dioxino[4,5-c]pyridine dichloride 2 in dichloromethane $(30 \mathrm{~mL})$, and the reaction mixture was stirred for 30 hours at reflux. Then, the precipitate was filtered off, and the solvent was removed in vacuo. The dry residue was purified using silica gel column chromatography (eluent ethyl acetate-petroleum ether, $1: 15)$. Yield $0.06 \mathrm{~g}$ (11\%), a yellow crystalline compound, m.p. ${ }^{99-101^{\circ} \mathrm{C} .} R_{f} 0.5$ (ethyl acetate : petroleum ether $1: 2) .{ }^{1} \mathrm{H}$ NMR $\left(400 \mathrm{MHz}, \mathrm{CDCl}_{3}\right)$ $\delta$, ppm: 1.54 (s, $\left.6 \mathrm{H}, \mathrm{C}\left(\mathrm{CH}_{3}\right)_{2}\right) ; 2.17\left(\mathrm{~s}, 3 \mathrm{H}, \mathrm{CH}_{3}\right) ; 2.42(\mathrm{~s}, 3 \mathrm{H}$, $\left.\mathrm{CH}_{3}\right) ; 3.91\left(\mathrm{~s}, 3 \mathrm{H}, \mathrm{CH}_{3} \mathrm{O}\right) ; 4.76\left(\mathrm{~s}, 2 \mathrm{H}, \mathrm{CH}_{2} \mathrm{O}\right) ; 6.89(\mathrm{ABX}$, $\left.{ }^{3} \mathrm{JHH}=8.0 \mathrm{~Hz}, \mathrm{C}_{6} \mathrm{H}_{3}\right) ; 7.04\left(\mathrm{ABX},{ }^{4} \mathrm{JHH}=1.6 \mathrm{~Hz}, \mathrm{C}_{6} \mathrm{H}_{3}\right) ; 7.10$ $\left(\mathrm{ABX},{ }^{3} \mathrm{JHH}=8.0 \mathrm{~Hz},{ }^{4} \mathrm{JHH}=1.6 \mathrm{~Hz}, \mathrm{C}_{6} \mathrm{H}_{3}\right) ; 7.13,7.52(\mathrm{AB}$, $\left.{ }^{3} \mathrm{JHH}=15.6 \mathrm{~Hz},-\mathrm{CH}=\mathrm{CH}-\right) .{ }^{13} \mathrm{C} \mathrm{NMR}\left(100 \mathrm{MHz}, \mathrm{CDCl}_{3}\right) \delta$, ppm: $\left.12.7\left(\mathrm{CH}_{3}\right) ; 18.7\left(\mathrm{CH}_{3}\right) ; 24.8\left(\mathrm{C}_{\left(\mathrm{CH}_{3}\right.}\right)_{2}\right) ; 56.0\left(\mathrm{CH}_{3} \mathrm{O}\right)$; $59.8\left(\mathrm{CH}_{2} \mathrm{O}\right) ; 99.3\left(\mathrm{C}\left(\mathrm{CH}_{3}\right)_{2}\right) ; 109.4$ (CHAr); 114.7 (CHAr); 120.5 (CHAr); 122.0 (-CH=CH-); 123.5 (CAr); 125.4 (CAr); 130.4 (CAr); 131.7 (-CH=CH-); 144.3 (CAr); 144.9 (CAr); 145.1 (CAr); 145.8 (CAr); 146.8 (CAr). MS (HRMS-ESI): found $[\mathrm{M}+\mathrm{H}]+342.1700 . \mathrm{C}_{20} \mathrm{H}_{24} \mathrm{NO}_{4}$. Calculated $[\mathrm{M}+\mathrm{H}]$ 342.1700 .

2.2. In Vitro Cytotoxicity Studies. Breast adenocarcinoma MCF-7 (ATCC ${ }^{\circledR}$ HTB-22 $2^{\mathrm{TM}}$ ), breast adenocarcinoma MDAMB-231 (ATCC HTB-26 ${ }^{\mathrm{TM}}$ ), glioblastoma SNB-19 (ATCC CRL-2219 $9^{\mathrm{TM}}$ ), human colon colorectal adenocarcinoma HCT-15 (ATCC CCL-225 ${ }^{\mathrm{TM}}$ ), and prostate adenocarcinoma PC-3 (GSM136316); kidney carcinoma A-498 (GSM136294); melanoma M-14 (GSM136320); ovary adenocarcinoma OVCAR-4 (GSM136312); non-small-cell lung carcinoma NCI-H322M (GSM136307); colorectal carcinoma HCT-116 (GSM136288), primary human foreskin fibroblast cells (HSF) isolated from the skin explant according to conventional protocol [15], and human embryonic kidney cells HEK-293 (ATCC CRL_1573 ${ }^{\mathrm{TM}}$ ) were cultured in $\alpha$-MEM (PanEko, Russia) supplemented with $10 \%$ fetal bovine serum (PAA, Australia), L-glutamine, and $1 \%$ penicillin-streptomycin at $37^{\circ} \mathrm{C}$ in a $5 \%$ humidified $\mathrm{CO}_{2}$ atmosphere in air. Cells were removed from the culture substrate by treatment with trypsin-EDTA with subsequent inactivation of trypsin by adding $\alpha$-MEM-containing serum. Cell suspensions were precipitated by centrifugation at $500 \mathrm{~g}$ and pellet was resuspended in phosphate buffered saline (PBS). Cell viability and density were measured in a Neubauer chamber by using $0.4 \%$ solution of trypan blue. Suspensions with the amount of viable cells no less than $90 \%$ were used in the experiments.
The effect of synthesized compounds on the proliferation of the cells was measured by MTT-assay (3-(4,5-dimethylthiazol-2-yl)-2,5-diphenyltetrazolium bromide) (Promega, USA). The cells were seeded in a 96-well plate at a concentration of 2000 cells per well and were cultured in supplemented $\alpha$-MeM $(180 \mu \mathrm{L})$ according to the standard culturing conditions for 1 day. The cell viability was measured at $72 \mathrm{~h}$ after treatment with the test agent $(20 \mu \mathrm{L})$. Then, the medium was exchanged for the supplemented medium $(80 \mu \mathrm{L})$. MTT solution $\left(5 \mathrm{mg} \mathrm{mL}^{-1}\right)$ was added to a volume of $20 \mu \mathrm{L}$ in each well and incubated for $3.5 \mathrm{~h}$. Then the solution was removed and DMSO $(100 \mu \mathrm{L})$ was added to solubilize the formazan crystals. After $10 \mathrm{~min}$, absorbance was measured at $555 \mathrm{~nm}$ (the reference wavelength $650 \mathrm{~nm}$ ) by a TECAN plate reader (Switzerland). The results were presented as the percent ratio to the control sample treated with PBS. For each compound tested, the $\mathrm{IC}_{50}$ values $(P<0.05)$ were generated from the dose-response curves for each cell line.

2.3. Visual Microscopy. Intracellular accumulation and distribution of compound $\mathbf{4 b}$ was assessed by confocal microscopy. Breast cancer cells MCF-7 were seeded into glass slides on a 6-well cultural plate in number of 200000 cells per well. Next day, compound $\mathbf{4 b}$ was added to each well in cultural media from the stock solution in DMSO to reach final concentration of $28 \mu \mathrm{M}$ and maintained 20 minutes at $37^{\circ} \mathrm{C}$. Then the cells were washed by Hanks's solution and fixed for $10 \mathrm{~min}$ at $4^{\circ} \mathrm{C}$ in $4 \%$ paraformaldehyde. Then the cover slides with the cells were washed again and transferred to microscope slides with the use of a mounting medium Shandon Consul-Mount (Thermo Scientific). The received slides were analyzed on Zeiss LSM 800 confocal laser scanning microscope with $\times 100$ immersion objective and $\times 20$ air objective. The samples with compound $\mathbf{4} \mathbf{b}$ were excited using $405 \mathrm{~nm}$ laser and detected in the range of $410-476 \mathrm{~nm}$.

\section{Results and Discussion}

The studied compounds were obtained from pyridoxine hydrochloride 1 according to our previously reported approach [8] (Scheme 1). The Wittig reactions of 2 monohydrate with various aromatic aldehydes $\mathbf{3 a} \mathbf{a}-\mathbf{c}$ were performed in $\mathrm{CH}_{2} \mathrm{Cl}_{2}$ in the presence of $\mathrm{NaH}$ (6 equiv.) at reflux for 30 hours. The target 5-methyl-6-alkenyl substituted derivatives $4 a-c$ with a trans-configuration of the alkene fragment were the major products of this reaction. The reaction typically led to a number of additional products such as cisalkenes, 5,6-bis-alkenyl substituted compounds, and some minor hyperconjugated structures. Compounds $4 \mathbf{a}-\mathbf{c}$ and a cis-alkene compound $\mathbf{5 b}$ could be separated from other products by silica gel column chromatography and were obtained in low to moderate isolated yields (9-30\%) as white and yellow crystalline substances. Characteristic features of compounds $4 \mathbf{a}-\mathbf{c}$ were the signals of trans-alkene protons at $6.50-7.70 \mathrm{ppm}$ (AB-pattern, ${ }^{3} J_{\mathrm{HH}}=15.6 \mathrm{~Hz}$ ). Synthesis and analytical characteristics of compounds $4 \mathbf{a}$ and $\mathbf{b}$ and $\mathbf{5 b}$ have been reported in our recent work [8], while compound $4 \mathrm{c}$ is described in this paper for the first time. 

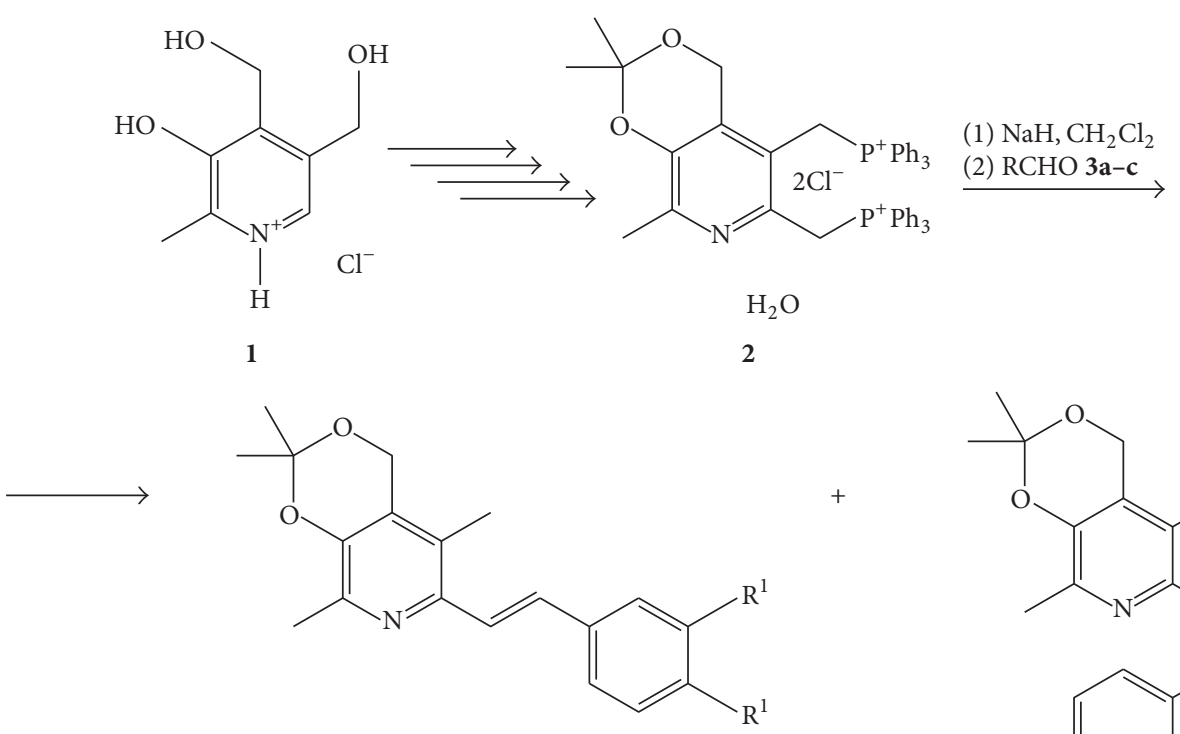

$$
\begin{aligned}
& \mathbf{4 a}, \mathrm{R}^{1}=\mathrm{R}^{2}=\mathrm{H}, 30 \%[8] \\
& \mathbf{4 b}, \mathrm{R}^{1}=\mathrm{R}^{2}=\mathrm{OCH}_{3}, 21 \%[8] \\
& \mathbf{4 c}, \mathrm{R}^{1}=\mathrm{OCH}_{3}, \mathrm{R}^{2}=\mathrm{OH}, 11 \%
\end{aligned}
$$<smiles>COc1ccc(/C=C\C2=NC(C)C3OC(C)(C)OCC3=C2C)cc1OC</smiles>

SCHEME 1: Synthesis of compounds studied in this work.

TABLE 1: Results of the cytotoxicity screening experiment against two cell lines.

\begin{tabular}{lccc}
\hline & \multicolumn{2}{c}{ Cytotoxicity, $\mathrm{IC}_{50} \mu \mathrm{M}$} & \multicolumn{2}{c}{ Selectivity index, } \\
& HEK-293 & MCF-7 & $\mathrm{IC}_{50 \text { HEK-293 }} / \mathrm{IC}_{50 \text { MCF-7 }}$ \\
\hline $\mathbf{4 a}$ & $2.7 \pm 0.3$ & $81.2 \pm 6.5$ & 0.03 \\
$\mathbf{4 b}$ & $22.8 \pm 2.4$ & $1.9 \pm 0.9$ & 12.0 \\
$\mathbf{4 c}$ & $>293.0$ & $7.9 \pm 4.9$ & 37.0 \\
$\mathbf{5 b}$ & $23.1 \pm 2.3$ & $32.4 \pm 2.6$ & 0.7 \\
$\mathbf{6 a}$ & $36.1 \pm 0.1$ & $67.8 \pm 1.0$ & 0.5 \\
$\mathbf{6 b}$ & $>306.0$ & $>306.0$ & 1.0 \\
$\mathbf{6 c}$ & $>320.0$ & $>320.0$ & 1.0 \\
Doxorubicin & $1.2 \pm 0.1$ & $1.2 \pm 0.1$ & 1.0 \\
\hline
\end{tabular}

The obtained compounds were screened for cytotoxicity against two cell lines, the estrogen-dependent MCF-7 (breast cancer) cells and the human embryonic kidney 293 (HEK293) cells (Table 1). To explore SAR dependencies, we also tested the three structurally related trans-5-phenylethenyl substituted pyridoxine derivatives 6a-c (Figure 2) described in our recent work [7]. The widely used anticancer anthracycline antibiotic doxorubicin was used as a broad-spectrum reference drug. In this screening experiment, compounds $\mathbf{4 b}$ and $\mathbf{4 c}$ demonstrated high cytotoxic activity against the MCF-7 cells with $\mathrm{IC}_{50}$ in the range of $1.9-7.9 \mu \mathrm{M}$, which is comparable to cytotoxic activity of the reference drug $\left(\mathrm{IC}_{50} 1.2 \mu \mathrm{M}\right)$. At the same time, the cytotoxic activity of $\mathbf{4 b}$ and $\mathbf{4 c}$ against the normal HEK-293 cells ( $\mathrm{IC}_{50} 22.8$ and<smiles>[R]c1ccc(/C=C/c2cnc(C)c3c2COC(C)O3)cc1[R]</smiles>

$$
\begin{aligned}
& \text { 6a, } R^{1}=R^{2}=H \\
& \text { 6b, } R^{1}=R^{2}=\mathrm{OCH}_{3} \\
& \text { 6c, } R^{1}=\mathrm{OCH}_{3}, R^{2}=\mathrm{OH}
\end{aligned}
$$

Figure 2: 5-Phenylethenyl substituted pyridoxine derivatives described in our recent work [5] and studied in the cytotoxicity screening experiment.

$>293 \mu \mathrm{M}$, respectively) was significantly lower than that of doxorubicin $\left(\mathrm{IC}_{50} 1.2 \mu \mathrm{M}\right)$. As a result, compounds $4 \mathbf{b}$ and 4c have significantly better selectivity index (SI 12 and 37, respectively) as compared to doxorubicin (SI 1.0).

Of note, the active compounds contain in their structures the hydroxy or methoxy groups in para-position of the phenyl ring, which is consistent with the general aforementioned SAR requirements for this class of ER modulators [16].

Compounds $\mathbf{4 b}$ and $\mathbf{4 c}$ were then tested against an extended panel of normal and cancer cell lines (Table 2). In agreement with our underlying theoretical hypothesis, a very good selectivity for the estrogen-dependent MCF-7 cell line was observed for the active compounds as compared to other 


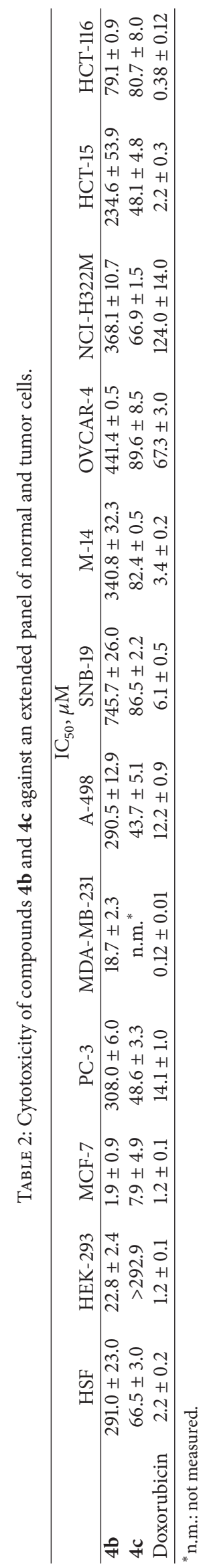




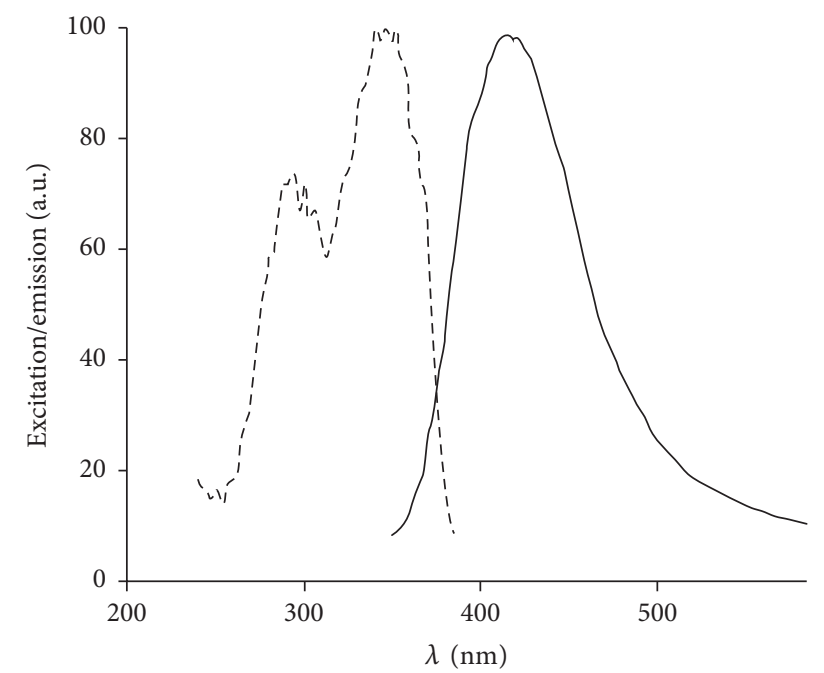

FIgUre 3: The excitation (dashed line) and emission (solid line) spectra of compound $\mathbf{4 b}$ (a.u.: arbitrary units).

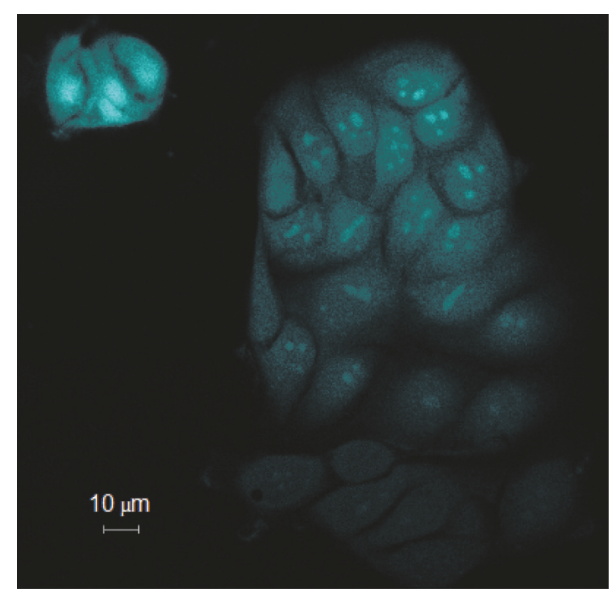

FIgURE 4: Microphotograph of MCF-7 cells incubated with $\mathbf{4 b}$ $(28 \mu \mathrm{M}, 20 \mathrm{~min}), \lambda_{\mathrm{em}} 420 \mathrm{~nm}$.

studied cells including the normal ones such as human fibroblast cells (HSF) and human embryonic kidney 293 (HEK-293) cells. Thus, the MCF-7 versus HSF selectivity indexes were 153 and 8.4 for compounds $\mathbf{4 b}$ and $\mathbf{4 c}$, respectively (not shown in the table). The leading compound $\mathbf{4 b}$ also demonstrated clear selectivity for MCF-7 as compared to ER negative MDAMB-231 breast cancer cells with the selectivity index $\sim 10$. This important observation suggests a potential role of estrogen receptors as primary targets for the active compounds.

An interesting and practically significant property of the studied compounds is their intense blue fluorescence with the maximum at $416 \mathrm{~nm}$ (Figure 3). The fluorescence appears as a result of $\pi$-conjugation in the trans-diarylethylene scaffold.

This feature allowed us to assess their cellular permeability using the visible light microscopy. Figure 4 demonstrates that one of the leading compounds $\mathbf{4 b}$ effectively penetrates through cellular membrane. It can be effectively visualized in cytoplasm and, moreover, is accumulated in nucleus, the cellular compartment where the ERs are localized.

The reasons for the observed effective penetration of the studied compounds through the cell membrane are probably related to their relatively high lipophilicity $(\log \mathrm{P}$ in the range of 4.3-4.5) and the presence of a basic aromatic nitrogen atom, which are optimal for effective passive diffusion through the lipid bilayers. On the other hand, the presence of pyridoxine moiety can enhance transmembrane transport of the obtained derivatives via active mechanisms. First of all, many cells have specific pyridoxine transporters in their membranes (e.g., [17]). Pyridoxine is a cofactor for more than 140 essential enzymatic reactions, and pyridoxine-modified molecules are often recognized by many pathogenic cells and microorganisms as endogenous. As a result, they have increased cellular permeability and increased bioactivity. For example, the development of pyridoxine-modified nanoparticles for efficient intracellular delivery of doxorubicin (DOXB6-SA-NP) was reported [18]. It was demonstrated that the treatment with DOX-B6-SA-NP kept higher doxorubicin accumulation inside the cells than conventional lipid nanoparticles.

\section{Conclusion}

Herein, we have described a novel pyridoxine-based chemotype of bioisosteric analogs of the natural and synthetic drugs based on trans-stilbene scaffold. Despite inherent complications, the synthetic route to these compounds is rather straightforward and can be performed in an industrial scale. The active compounds $\mathbf{4 b}$ and $\mathbf{4 c}$ demonstrate high activity against the estrogen-dependent MCF-7 (breast cancer) cell line with $\mathrm{IC}_{50}$ in the range of $1.9-7.9 \mu \mathrm{M}$ and very good selectivity for other studied tumor and normal cells. The leading compound $\mathbf{4 b}$ also demonstrated clear selectivity for estrogen-dependent breast cancer MCF-7 cells as compared to ER negative MDA-MB-231 breast cancer cells (selectivity index 10), suggesting a potential role of estrogen receptors as targets for the active compounds. The active compounds possessed an intense blue fluorescence with the maximum at $410-420 \mathrm{~nm}$, and this feature allowed us to assess their cellular permeability using the confocal microscopy. Thus, compound $\mathbf{4 b}$ could be effectively visualized in cytoplasm and in nucleus, where the ERs are localized.

The obtained results make the described chemotype a promising starting point for the development of new anticancer agents potentially useful in the therapy of the estrogen-dependent malignancies such as breast cancer or as a novel fluorescent probe for molecular biological applications. The active compounds are currently under active investigation within our group, and their in vitro and in vivo properties will be reported and discussed in a complementary paper.

\section{Conflicts of Interest}

The authors declare that there are no conflicts of interest regarding the publication of this manuscript. 


\section{Acknowledgments}

This work was supported by Program of Competitive Growth of Kazan Federal University.

\section{References}

[1] T.-Y. Shen, H. Jones, and C. P. Dorn, Mercaptoalkylpyridine Disulfides, U.S. Patent 4053606 A, 1977.

[2] Y.-C. Kim, K.-Y. Jung, and J. H. Cho, Novel Pyridine Carboxylic Acid Based Compound Used as a p2x1 and p2x3 Receptor Antagonist, a Production Method for the Same and a Composition Comprising the Same, U.S. Patent 20130040997, 2011.

[3] W. Korytnyk, S. C. Srivastava, N. Angelino, P. G. G. Potti, and B. Paul, "A general method for modifying the 2-methyl group of pyridoxol. Synthesis and biological activity of 2-vinyland 2-ethynylpyridoxols and related compounds," Journal of Medicinal Chemistry, vol. 16, no. 10, pp. 1096-1101, 1973.

[4] M. V. Pugachev, N. V. Shtyrlin, L. P. Sysoeva et al., "Synthesis and antibacterial activity of novel phosphonium salts on the basis of pyridoxine," Bioorganic and Medicinal Chemistry, vol. 21, no. 14, pp. 4388-4395, 2013.

[5] M. V. Pugachev, N. V. Shtyrlin, S. V. Sapozhnikov et al., "Bisphosphonium salts of pyridoxine: the relationship between structure and antibacterial activity," Bioorganic and Medicinal Chemistry, vol. 21, no. 23, pp. 7330-7342, 2013.

[6] A. D. Strelnik, A. S. Petukhov, I. V. Zueva et al., "Novel potent pyridoxine-based inhibitors of AChE and BChE, structural analogs of pyridostigmine, with improved in vivo safety profile," Bioorganic and Medicinal Chemistry Letters, vol. 26, no. 16, pp. 4092-4094, 2016.

[7] M. V. Pugachev, R. S. Pavelyev, T. N. Nguyen, A. G. Iksanova, O. A. Lodochnikova, and Y. G. Shtyrlin, "Synthesis and antitumor activity of pyridoxine monoalkenyl derivatives," Russian Chemical Bulletin, vol. 65, no. 2, pp. 532-536, 2016.

[8] M. V. Pugachev, T. M. Bulatov, T. T. Nguyen et al., "Wittig reactions of a bis-triphenylphosphonium pyridoxine derivative," Tetrahedron Letters, vol. 58, no. 8, pp. 766-769, 2017.

[9] B. R. Stranix, J. J. Wu, G. Milot et al., "Pyridoxine hydroxamic acids as novel HIV-integrase inhibitors," Bioorganic and Medicinal Chemistry Letters, vol. 26, no. 4, pp. 1233-1236, 2016.

[10] J.-X. Yu, W. Cui, V. A. Bourke, and R. P. Mason, "6-trifluoromethylpyridoxine: novel 19F NMR $\mathrm{pH}$ indicator for in vivo detection," Journal of Medicinal Chemistry, vol. 55, no. 15, pp. 6814-6821, 2012.

[11] W. Zhang, J. Yao, V. Pham et al., "Pyridoxine as a template for the design of antiplatelet agents," Bioorganic and Medicinal Chemistry Letters, vol. 14, no. 18, pp. 4747-4750, 2004.

[12] V. Pham, W. Zhang, V. Chen et al., "Design and synthesis of novel pyridoxine $5 /$-phosphonates as potential antiischemic agents," Journal of Medicinal Chemistry, vol. 46, no. 17, pp. 36803687, 2003.

[13] R. Turo, M. Smolski, R. Esler et al., "Diethylstilboestrol for the treatment of prostate cancer: Past, present and future," Scandinavian Journal of Urology, vol. 48, no. 1, pp. 4-14, 2014.

[14] F. Li, J. Dou, L. Wei, S. Li, and J. Liu, "The selective estrogen receptor modulators in breast cancer prevention," Cancer Chemotherapy and Pharmacology, vol. 77, no. 5, pp. 895-903, 2016.

[15] L. F. G. Rittie, Isolation and Culture of Skin Fibroblasts, Humana Press, Totowa, NJ, USA, 2010.
[16] A. Jameera Begam, S. Jubie, and M. Nanjan, "Estrogen receptor agonists/antagonists in breast cancer therapy: a critical review," Bioorganic Chemistry, vol. 71, pp. 257-274, 2017.

[17] N. Szydlowski, L. Bürkle, L. Pourcel, M. Moulin, J. Stolz, and T. B. Fitzpatrick, "Recycling of pyridoxine (vitamin B6) by PUP1 in Arabidopsis," Plant Journal, vol. 75, no. 1, pp. 40-52, 2013.

[18] S. Sharma, A. Verma, J. Singh et al., "Vitamin B6 tethered endosomal $\mathrm{PH}$ responsive lipid nanoparticles for triggered intracellular release of doxorubicin," ACS Applied Materials and Interfaces, vol. 8, no. 44, pp. 30407-30421, 2016. 

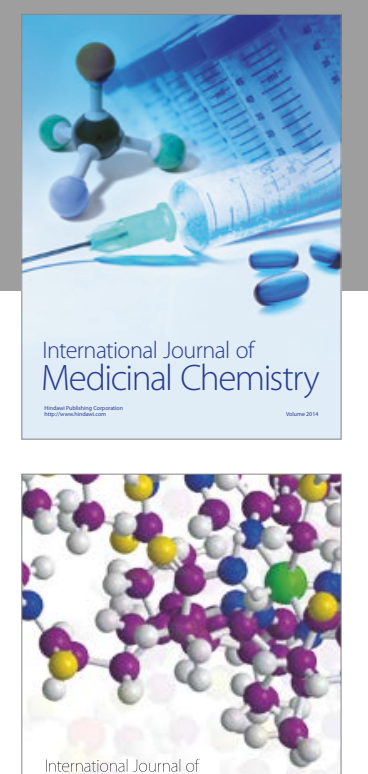

Carbohydrate Chemistry

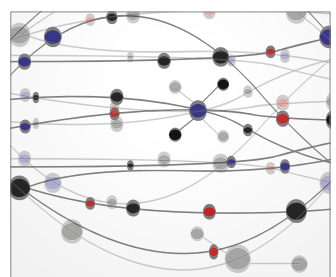

The Scientific World Journal
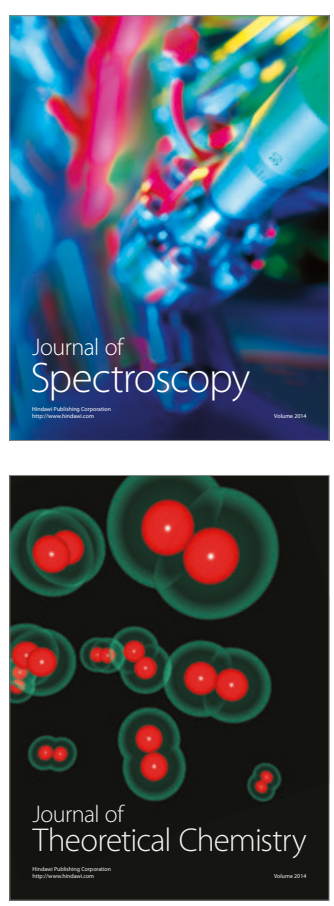
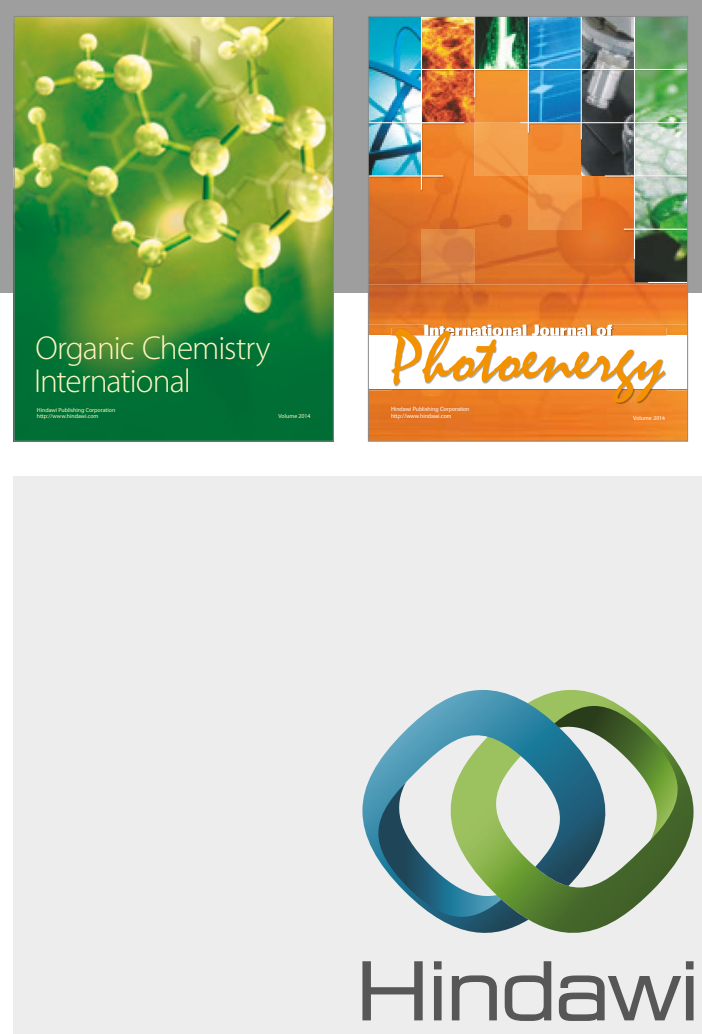

Submit your manuscripts at

https://www.hindawi.com

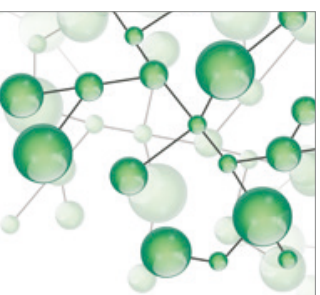

International Journal of

Inorganic Chemistry

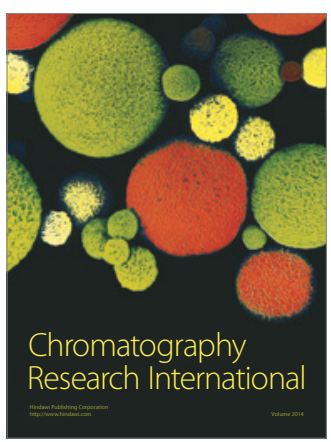

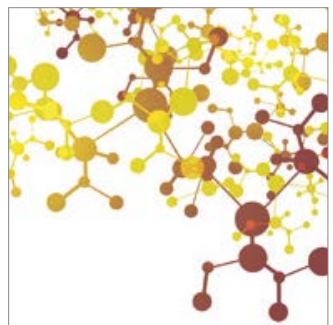

Applied Chemistry
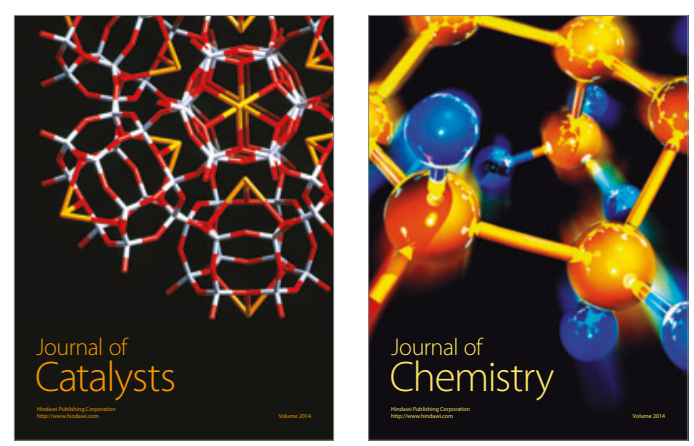
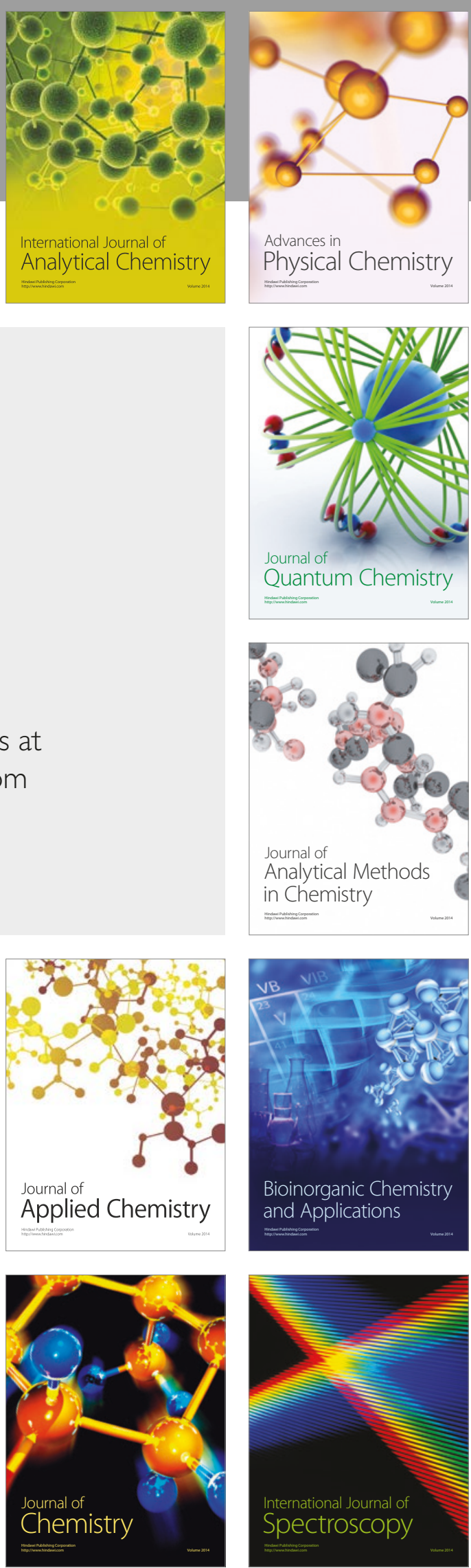